\title{
Analysis of Atmospheric Aerosols Using the Lisbon Nuclear Microprobe
}

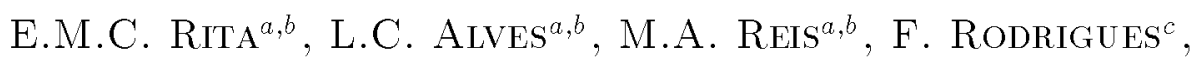 \\ P. Fialho ${ }^{c}$ AND J.C. Soares ${ }^{a, b}$ \\ ${ }^{a}$ Department of Física, Instituto Tecnológico e Nuclear \\ E.N.10, 2686-953 Sacavém Codex, Portugal \\ ${ }^{b}$ CFNUL, Av. Prof. Gama Pinto 2, 1699 Lisboa, Portugal \\ ${ }^{c}$ Department of Agrarian Sciences of the University of the Azores \\ 9701-851 Terra Chã, Angra do Heroísmo, Azores, Portugal
}

The nuclear microprobe installed at Instituto Tecnológico e Nuclear, in Lisbon, was used in the analysis of aerosols collected at the Azores islands. Samples from two different aerosol groups were analysed. One referred to aerosols that were carried from North America and the other one contained aerosols that were carried from the Sahara desert and crossed over Europe. Coarse and fine fractions were analysed for each aerosol group and two-dimensional elemental maps were constructed, which allowed the identification of several individual particles. For particles of interest, elemental spatial correlations and dimensions were determined and point analysis was also carried out (depth information was achieved by fitting Rutherford backscattering spectra). Some of these particles are quite interesting. For instance, in the fine fraction of the aerosols that were carried from North America, particles were found with $\mathrm{Cu}$ and $\mathrm{Cl}$ in the atomic proportion $1: 2$ and with dimensions $15 \times 15 \times 15 \mu \mathrm{m}^{3}$, and in the corresponding coarse fraction a particle with $\mathrm{K}$ and $\mathrm{S}$ was identified, with dimensions $28 \times 35 \times 30 \mu \mathrm{m}^{3}$. Some differences were found between the aerosols groups. One example of these are $\mathrm{Ti}$ particles (fine fraction) and $\mathrm{Rb}$ (coarse fraction) that were identified in one group (Sahara desert and Europe), but not in the other.

PACS numbers: 92.20.Bk, 92.60.Mt, 78.70.En, 82.80.Yc 


\section{Introduction}

In the last few years there has been a growing application of the nuclear microprobe in aerosol analysis. The power of this technique relies in the capability of performing microscopic analysis using the advantages of particle induced X-ray emission (PIXE) and Rutherford backscattering spectroscopy (RBS) simultaneously. In this way the spatial distribution of trace and matrix elements in the sample can be determined (PIXE and RBS spectra) and two-dimensional elemental maps constructed. Detailed point analysis may also be done. This kind of information is quite suitable for aerosols as particles can be visualized and elemental correlations and particle dimensions determined, including the thickness, which emerges from RBS spectra.

These were also the main reasons that lead us to the aerosol analysis with the nuclear microprobe installed at Instituto Tecnológico e Nuclear (ITN) in Lisbon. The aerosols samples were collected at Terceira Island, in Azores, and this pioneer work (at ITN) resulted from the cooperation of ITN with Azores University. Preliminary studies revealed two different origins for the collected aerosols, which allowed them to be separated into two different groups. Several interesting particles were identified in both groups, and for some of them, based on PIXE and RBS quantitative analysis, was possible to suppose the presence of compounds, such as $\mathrm{NaCl}, \mathrm{CaCO}_{3}, \mathrm{CaSO}_{4}$, and $\mathrm{Fe}(\mathrm{OH})_{3}$. The particle's main characteristics and the differences found between both groups of aerosols will be presented.

In data acquisition and treatment the $\mathrm{OM}_{-} \mathrm{DAQ}$ [1] (Oxford Microbeams ${ }^{\circledR}$ ) and DAN32 [2] programs were respectively used. The latest establishes an interface with the PIXE quantitative analysis program GUPIX [3] (Guelph University, in Canada), which makes use of the $Q$-factor method [4]. The potentialities of both programs (OM_DAQ and DAN32) as well as some analysis restrictions and limitations in this context will be mentioned.

\section{Experimental}

\subsection{Sample collection}

The aerosols were collected with a Sierra PM10 sampler, model SSI 120, using fibre filters for both fine $\left(D_{\mathrm{p}}<0.95 \mu \mathrm{m}\right)$ and coarse $\left(0.95 \mu \mathrm{m}<D_{\mathrm{p}}<10 \mu \mathrm{m}\right)$ fractions. Satellite observation of air mass movements allowed the definition of two different aerosol samples groups. Group NA refers to aerosols that were carried from North America and group ES contains aerosols that were carried from the Sahara desert and crossed over Europe [5]. The fine and coarse samples of groups $\mathrm{NA}$ and $\mathrm{ES}$ were designated by $\mathrm{NA}_{\mathrm{F}}$ and $\mathrm{NA}_{\mathrm{C}}$ and $\mathrm{ES}_{\mathrm{F}}$ and $\mathrm{ES}_{\mathrm{C}}$, respectively.

For the analysis, sections with dimensions $1 \times 1 \mathrm{~cm}^{2}$ of each filter were directly mounted in the microprobe sample holder and analyzed without any kind of previous treatment. 


\subsection{Data acquisition}

All the samples were bombarded with a $2 \mathrm{MeV}$ proton beam produced by a 3.1 MV Van de Graaff Accelerator. An Oxford Microbeam ${ }^{\circledR}$ nuclear microprobe was used, which allowed the proton beam to be focused to a $3 \mu \mathrm{m}$ diameter for a $100 \mathrm{pA}$ beam current. A detailed setup description can be found elsewhere [6]. A $50 \mu \mathrm{m}$ Mylar filter was placed in front of the Si(Li) detector used for PIXE analysis.

For all samples, scanning of $500 \times 500 \mu \mathrm{m}^{2}$ for fine filters and $2500 \times 2500 \mu \mathrm{m}^{2}$ for coarse filters, were first made, which allowed the identification of particles by visualizing the corresponding two-dimensional elemental maps. For some of these particles, smaller scans $\left(50 \times 50 \mu \mathrm{m}^{2}\right.$ and $100 \times 100 \mu \mathrm{m}^{2}$ for fine and coarse fractions, respectively) were made in order to construct new maps with the particles centred in them. All these scans were saved in list mode files. For some particles point measurements (PIXE and RBS spectra) were carried out, in order to get information with better statistics.

\subsection{Data processing and restrictions}

The particles dimensions and elemental correlations were determined from the two-dimensional X-ray elemental maps. Some of the list mode files were used in setting masks for interesting areas of the scanned field, and the corresponding PIXE and RBS spectra were constructed.

The PIXE and RBS spectra were analyzed with the DAN32 program, which includes GUPIX code for PIXE spectra fitting. The latest spectra gave information about the presence of elements with $Z>14$ and the corresponding concentrations (in ppm), while RBS fitting allowed the identification of the lightest elements ( N, F, C, O, and $\mathrm{Na}$ ), the determination of their depth profile and of the $Q$ factor [4], used by GUPIX in correcting the protons charge deposited on the sample for quantitative analysis of PIXE spectra. Fitting RBS spectra for this kind of samples (aerosols) may sometimes be a little bit complicated, not only due to samples heterogeneities and element diffusion, but also to the intrinsic contribution of the filter used for collection. In fact, entangled fibres filters (as the ones used in this work) are not so convenient for ion beam analytical techniques as polycarbonate Nuclepore type of Teflon filters. Nevertheless, care was taken in analysing just the identified particles for which the RBS detected elements clearly showed them as surface elements. In this way the possibility of combined analysis of the fibres themselves was minimized. In order to make the RBS fitting easier, the interelement atomic ratios of the major constituents obtained from the analysis of the PIXE spectra were used as a support for RBS fitting. Finally, from RBS results the most relevant interelement atomic ratios were derived, by calculating the weighted mean of the atomic proportions of each layer, and used in evaluating the presence of some compounds. 
During this data processing we had to account for some restrictions. One of them suffers from the fact that dead time correction and system calibration for the micro-PIXE setup is not well established, preventing an adequate quantitative analysis. Nevertheless, elemental ratios can be used with a good degree of confidence. The other one is related with the use of GUPIX and the particles multilayer characteristics found. In this work, several layers were considered for RBS fitting, indicating that the elements are distributed in slightly different proportions throughout the particle. The problem arises when we intend to use this matrix composition with GUPIX, since the program has a restriction: a visible element can only belong to one layer that should be indicated by the user. As it is easily understood, we would be making a huge mistake by considering the matrix composition from RBS and saying at the same time that one given visible element belonged only to one layer, when the RBS spectrum indicated that it could be found in several layers. Therefore, and because silica filters were used, the solution was to consider a matrix composition of $\mathrm{Si}$ (visible element) and $\mathrm{O}$ (invisible element) $100 \mu \mathrm{m}$ thick, and run GUPIX in matrix iteration mode.

In resume, the data treatment procedure consisted in PIXE and RBS spectra fitting, referents to masks and point analysis, and in calculating the interelement atomic ratios for PIXE and RBS. The $x$ and $y$ dimensions and the particles thickness resulted, respectively, from X-ray elemental maps and RBS spectra.

\section{Results and discussion}

\subsection{Virgin filter}

Previously to aerosol samples analysis, a $500 \times 500 \mu \mathrm{m}^{2}$ scan of a virgin filter was made. The corresponding RBS spectrum indicated that until a $15 \mu \mathrm{m}$ depth the filter was composed of $\mathrm{SiO}_{2}$ but at superior depths $\mathrm{Si}$ and $\mathrm{O}$ were present in a proportion of 1:5. This might be explained by the filter's structure (mesh), which altered the RBS spectrum's shape. The PIXE spectrum indicated also the vestigial presence of $\mathrm{K}, \mathrm{Ca}, \mathrm{Ba}$, and $\mathrm{Fe}$.

\subsection{Fine fraction}

The analysis of samples $\mathrm{NA} \mathrm{A}_{\mathrm{F}}$ and $\mathrm{ES}_{\mathrm{F}}$ revealed the presence of some particles quite interesting, whose main characteristics are resumed in Table I. The prominence goes to particles with $\mathrm{Cu}$ and $\mathrm{Cl}$, found only on sample $\mathrm{N} A_{F}$, of which PIXE and RBS results indicated the $\mathrm{CuCl}_{2}$ stoichiometry between these two elements. Nevertheless, particles with $\mathrm{Cu}$ and no $\mathrm{Cl}$ were identified in both samples, as well as particles with $\mathrm{Ca}$ and $\mathrm{Fe}$. In a similar way, some particles were found only on sample $\mathrm{ES}_{\mathrm{F}}$, such as particles with $\mathrm{Ti}$, with $\mathrm{Ca}$ and $\mathrm{S}$ and with $\mathrm{Ca}, \mathrm{Fe}$, and $\mathrm{Ti}$, possibly indicating a contribution of the Sahara desert. 
TABLE I

Results of PIXE and RBS spectra fits, referents to point analysis of particles found on samples $N A_{F}$ and $\mathrm{ES}_{\mathrm{F}}$.

\begin{tabular}{|c|c|c|c|c|c|}
\hline \multirow{3}{*}{ Sample } & \multirow{3}{*}{ Particle } & \multicolumn{4}{|c|}{ Results } \\
\hline & & \multicolumn{2}{|c|}{ Atomic proportions } & \multirow{2}{*}{$\begin{array}{c}\text { Possible } \\
\text { associations }\end{array}$} & \multirow{2}{*}{$\begin{array}{c}\text { Dimensions } \\
{\left[\mu \mathrm{m}^{3}\right]}\end{array}$} \\
\hline & & PIXE & RBS & & \\
\hline \multirow{3}{*}{$\mathrm{NA}_{F}$} & $\mathrm{Cu}, \mathrm{Cl}^{a}$ & $\mathrm{CuCl}_{2.5}$ & $\mathrm{CuCl}_{1.7}$ & $\mathrm{CuCl}_{2}$ & $12 \times 15 \times 3$ \\
\hline & $\mathrm{Cu}$ & - & - & organic compounds & $5 \times 11 \times 6$ \\
\hline & $\mathrm{Ca}, \mathrm{Fe}$ & $\mathrm{CaFe}_{0.03}$ & $\mathrm{CaFe}_{0.05}$ & organic compounds & $20 \times 15 \times 17$ \\
\hline \multirow{5}{*}{$\mathrm{ES}_{\mathrm{F}}$} & $\mathrm{Ca}, \mathrm{Fe}^{a}$ & $\mathrm{CaFe}_{0.08}$ & $\begin{array}{c}\mathrm{CaFe}_{0.16} \\
\mathrm{C}_{0.3} \mathrm{O}_{8}\end{array}$ & $\begin{array}{c}\mathrm{CaCO}_{3}, \mathrm{CaO} \\
\mathrm{Fe}(\mathrm{OH})_{3}\end{array}$ & $11 \times 15 \times 15$ \\
\hline & $\mathrm{Ti}^{a}$ & $\mathrm{TiFe}_{0.13}$ & $\mathrm{TiFe}_{0.17}$ & organic compounds & $6 \times 7 \times 1$ \\
\hline & $\mathrm{Ca}, \mathrm{S}$ & $\mathrm{CaS}_{1.4}$ & $\begin{array}{c}\mathrm{CaS}_{0.8} \\
\mathrm{C}_{0.6} \mathrm{O}_{11} \\
\end{array}$ & $\begin{array}{c}\mathrm{CaCO}_{3}, \mathrm{CaSO}_{4} \\
\text { organic compounds }\end{array}$ & $15 \times 13 \times 16$ \\
\hline & $\mathrm{Cu}$ & - & - & organic compounds & $6 \times 8 \times 6$ \\
\hline & $\mathrm{Ca}, \mathrm{Fe}, \mathrm{Ti}$ & $\begin{array}{c}\mathrm{CaFe}_{0.3} \\
\mathrm{Ti}_{0.17}\end{array}$ & $\begin{array}{l}\mathrm{CaFe}_{0.12} \mathrm{O}_{3} \\
\mathrm{C}_{0.25} \mathrm{Ti}_{0.17}\end{array}$ & $\begin{array}{c}\mathrm{CaCO}_{3} \\
\mathrm{CaO}, \mathrm{Fe}(\mathrm{OH})_{3}\end{array}$ & $14 \times 12 \times 13$ \\
\hline
\end{tabular}

${ }^{a}$ More particles were found with these characteristics.

It is interesting to note that in some cases, due to $\mathrm{C}$ and $\mathrm{O}$ found in RBS spectra, it was possible to suppose the presence of $\mathrm{CaCO}_{3}$ (from soil), $\mathrm{CaO}, \mathrm{Fe}(\mathrm{OH})_{3}$ (eventually formed in clouds [7]), and $\mathrm{CaSO}_{4}$, besides organic compounds. In both samples, some of the particles revealed also the presence of $\mathrm{N}, \mathrm{Cr}, \mathrm{Ni}, \mathrm{Zn}, \mathrm{Sr}$, and $\mathrm{W}$. In sample $\mathrm{ES}_{\mathrm{F}}$ there were also identified $\mathrm{F}, \mathrm{Mn}, \mathrm{Rb}$, and $\mathrm{Zr}$.

By comparing the PIXE results with the RBS results, we realize that there is good agreement between both techniques. The particles dimensions suggest that all have a shape close to spherical, except for the particles with $\mathrm{Cu}$ and $\mathrm{Cl}$ and with $\mathrm{Ti}$. This non-sphericity might have been a result of the violent impaction of these

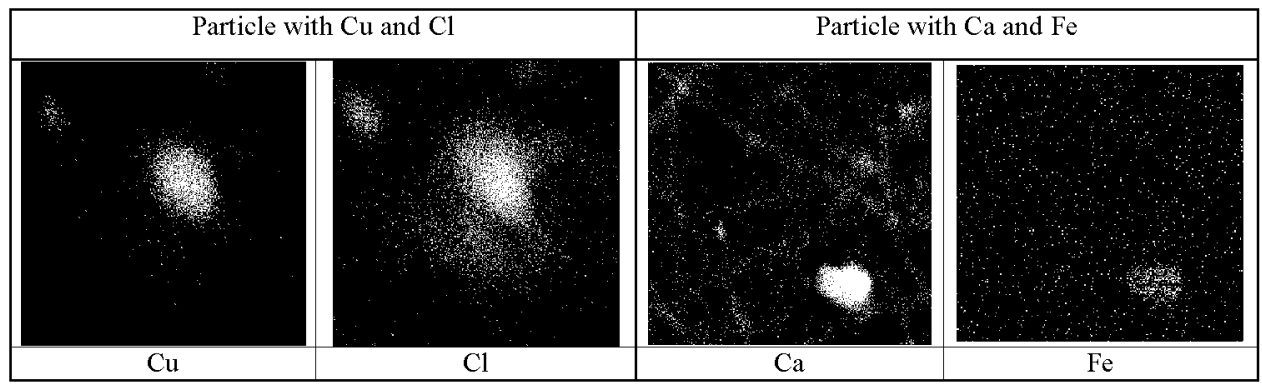

Fig. 1. Elemental maps where one can see one of the $\mathrm{Cu}$ and $\mathrm{Cl}$ particles (scan $\left.50 \times 50 \mu \mathrm{m}^{2}\right)$, another with $\mathrm{Ca}$ and $\mathrm{Fe}\left(\operatorname{scan} 150 \times 150 \mu \mathrm{m}^{2}\right)$ and the filter fibres. Bright and dark colours refer to high and low concentration, respectively. 
particles with the filter, during collection, combined with an organic compound origin or at least with a compound with very low density. The X-ray elemental maps of two of the particles found in these samples are shown in Fig. 1. Notice that the filter fibres are visible on the Ca map.

\subsection{Coarse fraction}

A large density of particles with $\mathrm{Cl}$ was found in samples $\mathrm{NA} \mathrm{A}_{\mathrm{C}}$ and $\mathrm{ES}_{\mathrm{C}}$. The expected marine contribution that could be revealed by the association of $\mathrm{Cl}$ and $\mathrm{Na}$ as $\mathrm{NaCl}$ was confirmed by fitting RBS spectra referents to areas with high and low $\mathrm{Cl}$ concentration (masks were set in these areas). In both samples were also found particles with $\mathrm{Ca}$ and $\mathrm{S}$, whose RBS fits indicated the presence of $\mathrm{CaCO}_{3}$ and $\mathrm{CaSO}_{4}$.

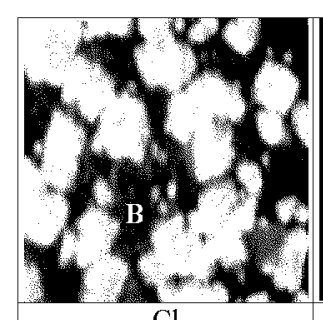

$\mathrm{Cl}$

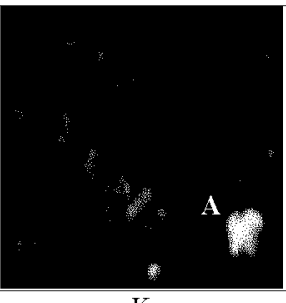

$\mathrm{K}$

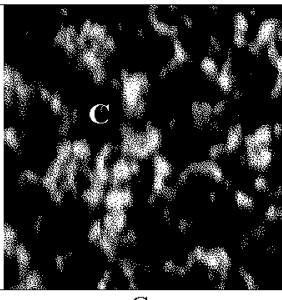

$\mathrm{Ca}$

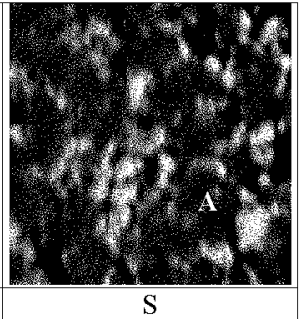

Fig. 2. Elemental maps referring to a $250 \times 250 \mu \mathrm{m}^{2}$ scan. A - particle with $\mathrm{K}$ and $\mathrm{S}$; $\mathrm{B}$ - particles with $\mathrm{Cl}$; $\mathrm{C}$ - particles with $\mathrm{Ca}$ and $\mathrm{S}$. Bright and dark colours refer to high and low concentration, respectively.

TABLE II

Results of PIXE and RBS spectra fits, referents to point analysis of particles found on samples $\mathrm{NA}_{\mathrm{C}}$ and $\mathrm{ES}_{\mathrm{C}}$.

\begin{tabular}{|c|c|c|c|c|c|}
\hline \multirow{3}{*}{ Sample } & \multirow{3}{*}{ Particle } & \multicolumn{4}{|c|}{ Results } \\
\hline & & \multicolumn{2}{|c|}{ Atomic proportions } & \multirow{2}{*}{$\begin{array}{c}\text { Possible } \\
\text { associations }\end{array}$} & \multirow{2}{*}{$\begin{array}{c}\text { Dimensions } \\
{\left[\mu \mathrm{m}^{3}\right]}\end{array}$} \\
\hline & & PIXE & RBS & & \\
\hline \multirow{4}{*}{$\mathrm{NA}_{\mathrm{C}}$} & $\mathrm{Cl}^{a}$ & - & $\mathrm{NaCl}_{0.8}$ & $\mathrm{NaCl}$ & $58 \times 94 \times 30$ \\
\hline & $\mathrm{K}, \mathrm{S}$ & $\mathrm{KS}_{0.6} \mathrm{Cl}_{0.7}$ & $\mathrm{KSCl}_{0.7}, \mathrm{Na}_{0.7}$ & $\mathrm{NaCl}$ & $28 \times 35 \times 30$ \\
\hline & $\mathrm{Ca}, \mathrm{S}$ & $\mathrm{CaS}$ & $\mathrm{CaS}_{0.7} \mathrm{O}_{5.4}, \mathrm{C}_{0.3}$ & $\mathrm{CaSO}_{4}, \mathrm{CaCO}_{3}$ & $17 \times 26 \times 17$ \\
\hline & $\mathrm{Fe}, \mathrm{Cu}$ & $\mathrm{FeCu}$ & $\begin{array}{c}\mathrm{Fe} \mathrm{Cu}_{0.9} \mathrm{O}_{0.7} \\
\mathrm{Cl}_{0.9} \mathrm{Na}_{0.9}, \mathrm{C}_{0.04}\end{array}$ & $\begin{array}{c}\mathrm{Fe}(\mathrm{OH})_{3}, \mathrm{NaCl} \\
\text { organic compounds }\end{array}$ & $9 \times 14 \times 25$ \\
\hline \multirow[b]{2}{*}{$\mathrm{ES}_{\mathrm{C}}$} & $\mathrm{Cl}$ & - & $\mathrm{NaCl}_{0.8}$ & $\mathrm{NaCl}$ & $38 \times 47 \times 22$ \\
\hline & $\mathrm{Ca}, \mathrm{S}$ & $\mathrm{CaS}_{0.8}$ & $\begin{array}{c}\mathrm{CaS}_{1.1} \mathrm{Fe}_{0.3} \\
\mathrm{C}_{1.3} \mathrm{O}_{10} \\
\end{array}$ & $\begin{array}{c}\mathrm{CaSO}_{4}, \mathrm{Fe}(\mathrm{OH})_{3} \\
\text { organic compounds }\end{array}$ & $19 \times 28 \times 21$ \\
\hline
\end{tabular}

\footnotetext{
${ }^{a}$ Results from masks set on these particles.
} 
The main differences that make the distinction between these coarse fraction samples are the presence of a particle with $\mathrm{K}$ and $\mathrm{S}$ in sample $\mathrm{NA}_{\mathrm{C}}$ and the identification of $\mathrm{Rb}$ and $\mathrm{Zn}$ in sample $\mathbf{E S}_{\mathrm{C}}$. In Fig. 2 elemental maps are shown where some of the principal particles identified on coarse fraction samples can be easily visualized.

Table II summarizes the main characteristics (dimensions, atomic proportions, and possible compounds) of all the particles analyzed in both samples.

From the fitted PIXE spectra we concluded that in relative terms (that's what we are interested in) the results are reliable. If we compare these results with the ones from RBS, we realize that there is agreement between both techniques.

As expected, the coarse fraction particles are bigger than the fine ones and also seem to have a spherical shape. However, we must be aware of the possibility of small particle overlap, giving the illusion of bigger particles.

\section{Conclusions}

The study here described is an example of the importance of the nuclear microprobe in aerosol analysis. The information extracted from two-dimensional elemental maps (elemental correlations and dimensions) along with the atomic proportions resulting from PIXE and RBS spectra fitting, allowed the characterization of particles. In some particular cases, it was possible to propose the hypothesis of the presence of $\mathrm{NaCl}, \mathrm{CaCO}_{3}, \mathrm{CaSO}_{4}$, and $\mathrm{Fe}(\mathrm{OH})_{3}$.

Several differences were found between the aerosols that passed over North America (group NA) and the ones that were carried from the Sahara desert and crossed over Europe (group ES). For the fine fractions, the most relevant are the identification of particles with $\mathrm{Cu}$ and $\mathrm{Cl}$ (1:2) only on group NA and of particles with $\mathrm{Ti}$, with $\mathrm{Ca}$ and $\mathrm{S}$ and with $\mathrm{Ca}, \mathrm{Fe}$, and Ti in group ES. Particles with $\mathrm{Cl}$ $(\mathrm{NaCl})$ were found all over the coarse fraction samples and a particle with $\mathrm{K}$ and $\mathrm{S}$ was identified in the coarse filter of group NA. It should be stressed that the small sample areas analyzed cannot be considered representative of the entire sample.

In spite of a data processing restriction (matrix composition for GUPIX) and an experimental setup calibration problem, the aim of the data handling procedures defined to solve these problems seems to have been accomplished. As a matter of fact, the intercomparison of PIXE and RBS elemental ratios indicates the agreement of these two powerful techniques and the success of the strategies defined to combine them.

\section{References}

[1] Installation and Operation Manual, Oxford Microbeams, Ltd., Oxford.

[2] G.W. Grime, presented at ICNMTA '96.

[3] J. Maxwell, J.L. Campbell, W.J. Teesdale, Nucl. Instrum. Methods Phys. Res. B 43, 218 (1989). 
[4] G.W. Grime, Nucl. Instrum. Methods Phys. Res. B 109/110, 170 (1996).

[5] NOAA Air Resources Laboratory, Backward Trajectories calculated by F. Rodrigues.

[6] L.C. Alves, M.B.H. Breese, E. Alves, A. Paúl, M.R. da Silva, M.F. da Silva, J.C. Soares, Nucl. Instrum. Methods Phys. Res. B 161-163, 334 (2000).

[7] J.H. Seinfeld, S.N. Pandis, Atmospheric Chemistry and Physics - From Air Pollution to Climate Change, Wiley, New York 1998. 